\title{
Prevalence of Chronic Diseases in Middle-Aged Women
}

\author{
Poorandokht Afshari ${ }^{1}$; Poorandokht Barzin ${ }^{1,} ;$ Shahnaz Najar ${ }^{1}$; Mohammadhosain \\ Haghighizade ${ }^{2}$ \\ ${ }^{1}$ Nursing and Midwifery College, Jundishapur University of Medical Sciences, Ahvaz, IR Iran \\ ${ }^{2}$ Health College, Jundishapur University of Medical Sciences, Ahvaz, IR Iran \\ ${ }^{*}$ Corresponding author: Poorandokht Barzin, Nursing and Midwifery College, Jundishapur University of Medical Sciences, Ahvaz, IR Iran. Tel: +98-9122001751/+98-6113738477, E-mail:
} Poorandokhtbarzin@yahoo.com

Received: April 28, 2014; Revised: May 16, 2014; Accepted: June 14, 2014

\begin{abstract}
Background: During middle age, a lot of changes happen in all physical, mental, social, and family aspects of women that may greatly affect the development of diseases and mortality risk.

Objectives: This research was conducted to determine the extent of chronic diseases in middle-aged women visiting healthcare treatment centers in Ahvaz.

Materials and Methods: This was a descriptive research study carried on 1266 women of 45-64 years old who were selected using the multistage sampling method. The necessary information was collected through a self-designed questionnaire and analyzed using SPSS V21. Descriptive statistics, $t$ test, and analysis of variance (ANOVA) was performed at 95\% level of confidence.

Results: Results showed that $46.8 \%$ of these women had one or more chronic diseases as follows: hypertension $12.5 \%$, diabetes mellitus $7.5 \%$, diabetes mellitus with heart diseases or high blood pressure $8.8 \%$, heart diseases $5.8 \%$, heart diseases together with high blood pressure $3.5 \%$, and other diseases $8.7 \%$. The effect of age, number of children, death of husband, occupation, ability to look after oneself, and do housework independently, degree of education, economic status $(\mathrm{P}<0.001)$, age at marriage, and ethnicity $(\mathrm{P}=0.001)$, on chronic diseases were significant.

Conclusions: Considering our results and high prevalence of chronic diseases, especially high blood pressure and diabetes mellitus, in middle-aged women, greater attention must be paid to the screening and monitoring programs of these chronic diseases.
\end{abstract}

Keywords:Middle-Aged; Chronic Diseases; Health Situation

\section{Background}

Women have been considered the main pillar of social development and the foundation for family health. They have important duties and roles in the family and society, and must be physically and mentally healthy to perform them $(1,2)$.

Middle age is one of the most important parts of a women's life, in fact, passing through middle age is a journey from youth to old age. It is a stage of growth that constitutes the greatest part of a woman's life $(3,4)$. Middleaged women usually confront problems such as physical and temperamental changes such as wrinkled face, body weakness, overweight, and bad temper. Consequently, they become susceptible to the feelings of lower selfconfidence, lack of control over their lives, feeling less well and worthy, living a low-quality life, and increased depression and psychological problems $(5,6)$.

Menopause is a critical stage in the life of a woman and the most important event in her life. During this stage, women develop many physical and psychological problems that reduce their quality of life (7). It is estimated that the number of menopausal women in the world will rise from the present number of 467 million to 1200 million in 2030; the greatest increase will be happening in the developing countries (8). It is also estimated that 5.3 million menopausal women live in Iran (9).

In middle-aged women, each lifestyle factor, independently affects (to a considerable degree) the development of many chronic diseases and mortality $(10,11)$. With growing old, the likelihood of developing one or more chronic diseases increases (12). Moreover, women spend at least one-third of their lives after menopause, during which menopausal manifestations such as osteoporosis, cardiovascular diseases, urogenital atrophy, and urinary incontinence develop $(13,14)$.

In Mashhad, Ramezanpour et al. conducted a study and showed that there was a correlation between cardiovascular diseases and insufficient physical activity in middleaged women (15). Press also reviewed previous researches and stated that there was a direct correlation between the risk of cardiovascular diseases and blood cholesterol level. He found that $45 \%$ of death cases resulting from coronary heart diseases in men, and $47 \%$ in women, were caused by

Copyright (C) 2014, Ahvaz Jundishapur University of Medical Sciences. This is an open-access article distributed under the terms of the Creative Commons Attribution-NonCommercial 4.0 International License (http://creativecommons.org/licenses/by-nc/4.0/) which permits copy and redistribute the material just in noncommercial usages, provided the original work is properly cited. 
increased blood cholesterol levels (16). Sharifrad carried out a study in Isfahan and observed that the prevalence of cardiovascular diseases in 30 to 79 years old people was $19.4 \%$ (21.9\% in women and $16 \%$ in men) (17).

\section{Objectives}

Because, there was no information available about the prevalence of chronic diseases in Ahvaz, this research was conducted to determine the frequency and types of chronic diseases in middle-aged women in this city.

\section{Materials and Methods}

The sample size, containing 1266 middle-aged women, was determined based on the conducted pilot study and on the frequency of prevalent diseases after statistical calculation with the following equation:

$\mathrm{N}=(\mathrm{Z} 21-\alpha / 2 \times \mathrm{P}(1-\mathrm{p}) / \mathrm{d} 2=1266$,

where $\mathrm{P}=0.05, \mathrm{~d}$ (accuracy) $=0.012$, and $\mathrm{Z}_{1-\alpha / 2}=1.96(95 \% \mathrm{CI})$.

This was a descriptive research, and the study population comprised the middle-aged women of Ahvaz, randomly chosen by selected infirmaries. The criteria for participating in the research were the participants' age (45-64 years old) and their willingness to take part in the research. Selection of the women was based on the questionnaire, statements made by them, the results of a screening research carried out in 2013, and the diagnoses of the physicians treating them. Since there are two healthcare treatment centers in Ahvaz, located in the east and the west of the city (each including many infirmaries), we used a multistage sampling (cluster random sampling) method.

First, the city area was divided into various clusters and then six centers (numbers 1 and 3 from the east and numbers 4 and 8 from the west healthcare and treatment centers) were randomly selected. The number of women selected from each center was proportionate to the number of families living within the area where the center was located. Therefore, the greater the population covered by a center, the more would be the selected women from that center. Selection of the middle-aged women was carried out by referring to the available family files and writing down their addresses and telephone numbers. Then visits were paid to these families, and the questionnaire was completed by interviewing the middle-aged women. If nobody was found at any of these addresses, the neighbor on the left-hand side or on the right-hand side was selected as the substitute. This process continued until the sample size was achieved.

Before completing the questionnaire, the participants were presented necessary explanations. Then, the interviews were conducted after obtaining their oral and written consent, and informing them their confidentiality, as well as their freedom to leave the interview at any moment. The questionnaire in this research was a self-designed one made up of two parts. The first part contained 19 demographic questions; the second part had 12 techni- cal questions concerning affliction with chronic diseases, symptoms and side effects, and medicines taken. The content validity method was used to make the questionnaire scientifically valid. After making the necessary corrections, the final version of the questionnaire was developed. Thirty qualified people filled the questionnaire to confirm its reliability and the results were studied with respect to continuity, and homogeneity of the answers using Cronbach $\alpha$, Pearson correlation coefficient, and the test-retest method. The reliability of the questionnaire was found to be $85 \%$.

The collected data was analyzed using SPSS V21 for performing descriptive statistics (percentages and frequencies to determine the frequencies of affliction with chronic diseases), and inferential statistics (the t test to compare the means of the variables between the two groups of afflicted with and not afflicted with chronic diseases, and analysis of variance [ANOVA] for comparing the means of the variables among several groups). The selected CI was $95 \%$.

\section{Results}

\subsection{Personal Data}

A total of 1266 middle-aged women were interviewed. Their average age was $51.63 \mathrm{y}$ with $45 \mathrm{y}$ being the most frequent age. The average age of the healthy ones was 50.01y and that of the sick ones $53.48 \mathrm{y}$. The educational level of participants were as follows: $5.7 \%$ had university degrees, $22 \%$ high school diplomas, $14.8 \%$ guidance school certificates, $26.4 \%$ passed elementary school education, and $31 \%$ were illiterate. Regarding marital status, $80.8 \%$ were married, $16.5 \%$ were widows, $1.8 \%$ divorced, and $0.9 \%$ single. Sixteen point five percent had occupations or received their deceased husbands' pensions, and 83.5\% were housewives. Their average age at marriage was $17.97 \mathrm{y}$; and their average number of children was 4.71 . Of them, $3 \%$ did not have any children, $2.4 \%$ had one child, $8.7 \%$ two, $16.4 \%$ three, and $70.5 \%$ more than four children. With regard to their income, $20.2 \%$ enjoyed a desirable monetary status, $65.2 \%$ somewhat desirable, and 14.67 felt undesirable. About $80.7 \%$ of the participants took care of their husbands and $19.3 \%$ took care of themselves or others. Finally, $95.3 \%$ of the studied women could look after themselves and do their housework independently, while $4.7 \%$ could not.

\subsection{Relative Frequencies of Chronic Diseases}

Results showed that $46.8 \%$ of the women had one or more of the following chronic diseases (Table 1): heat diseases, hypertension, diabetes, thyroid problems, osteoporosis, hyperlipidemia, and endometrial cancer (Figure 1). Hypertension with $12.5 \%$ was the most prevalent chronic disease. Other diseases were as follows: diabetes mellitus accompanied with heart diseases or hypertension $8.8 \%$, diabetes mellitus $7.5 \%$, heart diseases $5.8 \%$, 
heart diseases accompanied with hypertension 3.5\%, and other diseases $8.7 \%$.

\subsection{Factors Related to Chronic Diseases}

Frequencies of chronic diseases in the middle-aged

Table 1. Absolute and Relative Frequencies of Chronic Diseases in Units Under Study ${ }^{\mathrm{a}}$

\begin{tabular}{lc}
\hline Variables & Values \\
\hline Afflicted with chronic diseases & $592(46.8)$ \\
Not afflicted with chronic diseases & $674(53.2)$ \\
Total number of participants & $1266(100)$ \\
\hline a
\end{tabular}

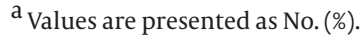

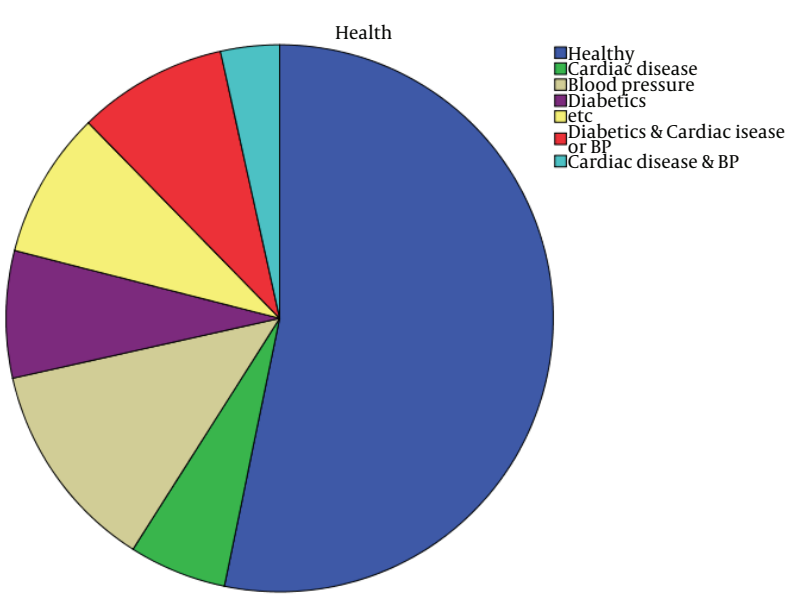

Figure 1. Distribution of Absolute and Relative Frequencies of Various Chronic Diseases in Studied Cases.

women were analyzed based on their demographic characteristics with the help of the $t$ test and ANOVA. Results indicated that chronic diseases had significant correlations with the variables of age $(P=0.000)$, age at marriage $(P=0.001)$, degree of education $(P=0.000)$, and the number of children $(P=0.000)$. Moreover, the effect of many factors such as death of husband $(\mathrm{P}=0.000)$, occupation $(\mathrm{P}=0.000)$, ability to take care of oneself and do housework independently $(\mathrm{P}=0.000)$, economic status $(\mathrm{P}=0.000)$, being in charge of the family $(\mathrm{P}=0.000)$, and ethnicity $(\mathrm{P}=0.001)$ on the occurrence of chronic diseases was significant.

\section{Discussion}

Our results indicated that cardiovascular diseases and hypertension constituted 21.5\% (cardiovascular diseases $5.8 \%$, hypertension $12.5 \%$, and cardiovascular diseases accompanied by hypertension 3.5\%), and diabetes mellitus $16.3 \%$ (7.5\% alone and $8.8 \%$ together with heart diseases or hypertension) of chronic diseases in these middle-aged women. Siam (2004) reported that in his study, $18.82 \%$ of men and $25.8 \%$ of women suffered from cardiovascular diseases (18), and in the similar researches, the prevalence of hypertension was reported to be $41.5 \%$ (14), $48 \%$ (9), $40 \%$ (17), and $62 \%$ (18), and the prevalence of diabetes mellitus were $15.6 \%(14), 14 \%$ (16), and 26.3\% (19).

In this study, $34.4 \%$ of the women reported to be afflicted with at least one chronic disease, while in other studies, the percentages of middle-aged women with at least one chronic disease were $78 \%, 87.6 \%$, and $82 \%$, and the percentage suffering from two chronic diseases was $12.3 \%$. Differences in race, economic or social status, healthcare systems, the type of the questionnaires, and different studied populations (middle-aged women of 45-54 years of age in this study and 60 years old or older in other studies) could explain these different figures. Considering our findings regarding the high frequencies of chronic diseases, especially hypertension and diabetes mellitus, in middle-aged women, greater attention must be paid to the screening and monitoring of these diseases.

Results indicated that factors such as death of the husband, occupation, ability to look after oneself and do housework independently, economic status, and ethnicity are related to the frequencies of chronic diseases in middle-aged women, and that the variables of age, degree of education, age at marriage, and number of children significantly influence occurrence of chronic diseases.

On the one hand, middle age itself has the greatest social and psychological effects and is accompanied with key changes in life, including biological ones like changes in health status, reduction in physical power, changes in appearance, as well as other changes such as death of family members or friends, job changes, changes in attitude, and finally transitional stages like menopause and children leaving the family. Usually, combinations of complex feelings and various patterns of response to changes are observed in these years $(20,21)$. On the other hand, Ribeiro et al. (2) reported in 2005 that, besides inability (including inability in looking after oneself and doing housework) and marital problems, the main health problem in middle-aged and old women was diabetes mellitus (which must be prevented or reduced in suitable ways) (22).

Degree of education is also an important factor in developing chronic diseases. Of course, this level is comparable with the degree of education in the whole population; therefore, it can be considered a potential risk factor in the occurrence of chronic diseases. Shaker et al. (2012) conducted a study in Kermanshah and found that low socioeconomic status was also a risk factor. Since low-income and lack of job security can directly result in economic stress, they can be considered one of the prevalent risk factors among research samples (23). These results especially conform to women whose husbands have passed away and do not receive their husbands' salaries.

This research did not have any special restrictions. It was registered in the Office of the Research Deputy Presi- 
dent of Jundishapur University of Ahvaz and received the ethical code "ajums.REC.1393.7" from this Office.

Findings in this study indicated the high frequency of chronic diseases, especially hypertension and diabetes mellitus in middle-aged women. Therefore, greater attention must be paid to the screening for and monitoring of these diseases. On the other hand, the ever-increasing population of middle-aged women necessitates the establishment of public centers for continuous monitoring of their situation and evaluating their problems so that required steps are taken, in coordination with other related organizations, to improve their situation.

\section{Acknowledgements}

We would like to express our gratitude to the Research Deputy of Jundishapur University of Medical Sciences for supporting this research. We also thank the middle-aged women who cooperated with us in carrying out this research with their utmost patience and self-possession.

\section{Funding/Support}

It was registered as project B-9302 in the Office of the Research Deputy President of Jundishapur University of Medical Sciences.

\section{References}

1. In: Shokravi FA, Alhani F, KazemNejad A editors. The relationship between physical activity andWomens Quality of life. The Third National Quality of life congress. 2004 Tehran.

2. Ribeiro PS, Jacobsen KH, Mathers CD, Garcia-Moreno C. Priorities for women's health from the Global Burden of Disease study. Int J Gynaecol Obstet. 2008;102(1):82-90.

3. Tsao LI, Su MC, An C. [Multidimensional impacts of transitional mid-life healthcare]. Hu Li Za Zhi. 2004;51(1):9-13.

4. Kase NG. Impact of hormone therapy for women aged 35 to 65 years, from contraception to hormone replacement. Gend Med. 2009;6 Suppl 1:37-59.

5. McKinley NM, Lyon LA. Menopausal attitudes, objectified body consciousness, aging anxiety, and body esteem: European American women's body experiences in midlife. Body Image. 2008;5(4):375-80.
6. Amore M, Di Donato P, Berti A, Palareti A, Chirico C, Papalini A, et al. Sexual and psychological symptoms in the climacteric years. Maturitas. 2007;56(3):303-11.

7. Shouhani M, Rasouli F, Haji Amiri P, Mahmoudi M. The Survey of Physical and Mental Problems of Menopause Women Referred to Liam Health Care Centers. IJNR. 2007;2(5):57-68.

8. Esmaeili H, Alimi R, Javanrooh N. Age at Menopause and Associated Factors in Middle-Aged Women in Mashhad City. Iran J Ob Gyn Ifer. 2012;15(36):1-7.

9. Sharifniya H, Bahrami N, Saatsaz S, Soleimani MA, Nazari R, Tabar RM. Assessment of Life Quality of Menopausal Women and Its Relative Factors. Iran J Ob Gyn Ifer. 2012;15(31):7-12.

10. Mahalik JR, Burns SM, Syzdek M. Masculinity and perceived normative health behaviors as predictors of men's health behaviors. Soc Sci Med. 2007;64(11):2201-9.

11. van Dam RM, Li T, Spiegelman D, Franco OH, Hu FB. Combined impact of lifestyle factors on mortality: prospective cohort study in US women. BMJ. 2008;337:a1440.

12. Aldrich N, Benson WF. Disaster preparedness and the chronic disease needs of vulnerable older adults. Prev Chronic Dis. 2008;5(1).

13. Ashrafi M, Ashtiani SMK, Ishrat B, Kashfi F, Malekzadeh F, Amirchqmaqy E:. Themeanage at menopause, and factorsaffectingthe prevalence of Tehran city residents. Kowsar Med J. 2007;12(1):75-82.

14. Berek JS, Novak E. Berek \& Novak's Gynecology.Philadelphia: Lippincott Williams \& Wilkins; 2007.

15. Ramezanpour MR, Hijazi M, HosseinNejad M. The Comparison of HS-CRP, TG, LDL-c and HDL-c in Active and Non Active Middleaged Women. Life Sci J. 2013;56(2):93-8.

16. Taheri L. The Effects of 8 week Aerobic Exercise on Blood Lipoprotein of Non-Athletic Middle-Aged Women of Ahvaz. Harakat. 2007;9(1):87-99.

17. Sarrafzadegan N. Research Project to Investigate Cardiovascular Risk Factors in Urban Areas of Isfahan. Tehran: Ministry of Health and Medical Education; 2004.

18. ABS. The Health of Older People, Australia, 2001. Australia: Australian Bureau of Statistics; 2004.

19. Hosseini SR, Zabihi A, Savad Kouhi S, Bizhani A. Prevalence of Chronic Diseases in Elderly Population in Amirkola . JBUMS. 2008;10(2):68-75.

20. Dennerstein L, Dudley EC, Hopper JL, Guthrie JR, Burger HG. A prospective population-based study of menopausal symptoms. Obstet Gynecol. 2000;96(3):351-8.

21. Blake J. Menopause: evidence-based practice. Best Pract Res Clin Obstet Gynaecol. 2006;20(6):799-839.

22. Wray LA, Ofstedal MB, Langa KM, Blaum CS. The effect of diabetes on disability in middle-aged and older adults. J Gerontol A Biol Sci Med Sci. 2005;60(9):1206-11.

23. Shaker J, Jaberghaderi N, Rezaei M. Psychosocial risk factors in patients with cardiovascular diseases in Kermanshah.J Kermanshah Univ Med Sci. 2012;16(3):246-54. 